\title{
Effects of live yeast on differential genetic and functional attributes of rumen microbiota in beef cattle
}

\author{
Ibukun M. Ogunade* (D), Jerusha Lay, Kenneth Andries, Christina J. McManus and Frederick Bebe
}

\begin{abstract}
Several studies have evaluated the effects of live yeast supplementation on rumen microbial population; however, its effect on differential microbial genes and their functional potential has not been described. Thus, this study applied shotgun metagenomic sequencing to evaluate the effects of live yeast supplementation on genetic and functional potential of the rumen microbiota in beef cattle. Eight rumen-cannulated Holstein steers were randomly assigned to two treatments in a cross-over design with two 25-day experimental periods and a 10-day wash-out between the two periods. The steers were housed in individual pens and fed 50\% concentrate-mix and 50\% red clover/orchard hay ad libitum. Treatments were (1) control (CON; basal diet without additive) and (2) yeast (YEA; basal diet plus $15 \mathrm{~g} / \mathrm{d}$ of live yeast product). Rumen fluid samples were collected at 3, 6, and $9 \mathrm{~h}$ after feeding on the last $d$ of each period. Sequencing was done on an Illumina HiSeq 2500 platform. Dietary yeast supplementation increased the relative abundance of carbohydrate-fermenting bacteria (such as Ruminococcus albus, $R$. champanellensis, R. bromii, and R. obeum) and lactate-utilizing bacteria (such as Megasphaera elsdenii, Desulfovibrio desulfuricans, and D. vulgaris). A total of 154 differentially abundant genes (DEGs) were obtained (false discovery rate $<0.01$ ). Kyoto Encyclopedia of Genes and Genomes (KEGG) annotation analysis of the DEGs revealed that 10 pathways, including amino sugar and nucleotide sugar metabolism, oxidative phosphorylation, lipopolysaccharide biosynthesis, pantothenate and coenzyme A biosynthesis, glutathione metabolism, beta-alanine metabolism, polyketide sugar unit biosynthesis, protein export, ribosome, and bacterial secretory system, were enriched in steers fed YEA. Annotation analysis of the DEGs in the carbohydrate-active enzymes (CAZy) database revealed that the abundance of genes coding for enzymes belonging to glycoside hydrolases, glycosyltransferases, and carbohydrate binding modules were enriched in steers fed YEA. These results confirm the effectiveness of a live S. cerevisiae product for improving rumen function in beef steers by increasing the abundance of cellulolytic bacteria, lactic acid-utilizing bacteria, and carbohydrate-active enzymes in the rumen.
\end{abstract}

Keywords: Functional potential, Live yeast, Rumen

\section{Background}

Live yeast products containing Saccharomyces cerevisiae are feed additives used to alter rumen fermentation for improved performance, health, and feed efficiency of ruminants [1]. Yeast products favor the growth of fiberdegrading bacteria, stabilize rumen $\mathrm{pH}$ by stimulating the population of lactate-consuming bacteria, and increase abundance of rumen microbes by reducing the rumen's redox potential [1].

\footnotetext{
* Correspondence: ibukun.ogunade@kysu.edu; Ibukun.ogunade@kysu.edu College of Agriculture, Communities, and the Environment, Kentucky State University, Frankfort, KY 40601, USA
}

Given the role of live yeast product on rumen function, earlier studies utilized culture-based methods to assess the effects of live yeast in the rumen [2]; however, this technique is unable to cultivate most naturally occurring species in the rumen [3]. In recent years, several $16 \mathrm{~S}$ ribosomal ribonucleic acid (rRNA) gene-based sequencing studies have advanced our knowledge of ruminal bacterial diversity and have reported the effects of $S$. cerevisiae products in the rumen [4]. However, 16S rRNA gene sequencing reveals the bacterial diversity without any insight into the functional potential of microbial communities [5]. In our recent companion study, 
belonging to the same feeding experiment as the current study [6], we integrated 16S rRNA gene sequencing and liquid chromatography-mass spectrometry-based metabolomics. Our results revealed that some bacterial genera that responded to treatment with a live S. cerevisiae-based additive showed positive correlations with metabolites involved in amino acid metabolism and biosynthesis as well as metabolism of energy substrates. Therefore, this study applied a shotgun metagenomic sequencing approach to offer taxonomic classification of sequences at the species level and reveal, for the first time, the effects of live yeast supplementation on differentially abundant genes and their functional potential.

\section{Methods}

All experimental animals were managed according to guidelines approved by the Institutional Animal Care and Use Committee of Kentucky State University (protocol number 18-001). Detailed information about cows and feeding have been reported in our companion paper [6]. Briefly, eight rumen-cannulated Holstein steers were assigned randomly to one of two treatments in a crossover design with two 25-day experimental periods and a 10-day wash-out between periods. The steers were housed in individual pens and fed 50\% concentrate-mix and 50\% red clover/orchard hay ad libitum. Mineral mix (Hubbard Feeds; Mankato, MN) was fed free-choice. Dietary treatments were (1) control (CON; basal diet without additive) and (2) yeast (YEA; basal diet plus $15 \mathrm{~g} / \mathrm{d}$ of Peloton live yeast product; PMI, Arden Hills, MN, USA). The yeast additive was top-dressed on the concentrate mix from $\mathrm{d} 1$ to 25 of each period.

\section{Rumen fluid collection}

On d 25 of each experimental period, representative samples $(100 \mathrm{~mL})$ of the ruminal contents were collected via the cannula at approximately 3,6 , and $9 \mathrm{~h}$ after feeding. At the time of collection, the samples were hand-strained through 4 layers of sterile cheesecloth to separate the liquid and solid samples. Daily composited samples (solid and liquid samples) were mixed $1: 1(w / w)$ and stored at $-80{ }^{\circ} \mathrm{C}$ for subsequent shotgun metagenomic sequencing.

\section{Shotgun metagenomic sequencing}

Deoxyribonucleic acid (DNA) extraction and sequencing were performed as reported by Ogunade et al. [7]. Briefly, rumen fluid samples were thawed at room temperature and centrifuged at $15,000 \times g$. DNA was extracted and purified from the pellets using a PowerSoil DNA Isolation Kit (MO BIO Laboratories Inc., Carlsbad, CA). The integrity of the DNA was verified by agarose $(0.7 \%)$ gel electrophoresis and the DNA was stored at $-20^{\circ} \mathrm{C}$ until further use. The sequencing library was constructed by DNA fragmentation
[8]. The sheared DNA fragments were then sequenced on an Illumina HiSeq 2500 platform using an Illumina HiSeq - paired-end 150 base pair (bp) strategy. Quality control was performed at each step of the procedure to guarantee the reliability of the sequence data.

\section{Bioinformatics and statistical analysis}

The raw sequence data files were demultiplexed and stored as fastq format. Quality filtering, such as removal of low-quality $(\mathrm{Q}$-score $\leq 10)$ and contaminative reads, was performed. Thereafter, the quality-filtered sequence data were assembled using Iterative De Bruijn Graph De Novo Assembler [9]. The resulting contig sequences $(\geq$ $500 \mathrm{bp}$ ) were evaluated using Quality Assessment Tool for Genome Assemblies (QUAST) software [10]. Thereafter, the contig sequences were aligned to National Center for Biotechnology Information's reference sequence database using Kraken software [11] to obtain taxonomic composition and relative abundance information. Differences in the relative abundance of taxa at the species level $(>0.1 \%$ of total sequences) were analyzed using the generalized linear mixed model procedure in SAS version 9.4 (SAS Institute Inc., Cary, NC, USA); the model included the effects of treatment, period, and their interaction. Differences between means were determined using the Fisher's test and significant differences were declared at $P \leq 0.05$ and tendency was declared at $0.05<P \leq 0.10$. Normality was tested by examining the distribution of residuals.

The open reading frames in the assembled contigs were predicted using GeneMark software [12]. Redundancy was removed and all predicted genes were clustered using Cluster Database at High Identity with Tolerance (CDHIT) software (http://www.bioinformatics.org/cd-hit/) with the following parameters: $90 \%$ similarity, $90 \%$ coverage threshold [13]. Differential gene abundance analysis between CON and YEA was performed using DESeq [14]. Fold change (the ratio of abundance between CON and YEA treatments) $\geq 2$ and false discovery rate $(\mathrm{FDR})<0.01$, obtained using the Benjamini-Hochberg calibration method, were set as screening criteria to obtain differential gene sets. The differential gene sets were annotated in Kyoto Encyclopedia of Genes and Genomes database (KEGG) pathways to reveal information on differential gene functional potential and the carbohydrate-active enzymes (CAZy) database (http:// www.cazy.org/) to obtain information on carbohydrate-active enzymes.

\section{Results and discussion}

The modes of action of several yeast products vary due to differences in yeast strain, composition, processing effect, and yeast cell wall constituents. Therefore, comparisons of responses to yeast supplementation among 
studies require caution and clarification [6]. The product used in this study is a thermal-stable live $S$. cerevisiae $\left(5.7 \times 10^{6}\right.$ colony forming units/g) with high levels of mannan oligosaccharides and beta-glucans, which were sourced from human-grade food plant (PMI, Arden Hills, MN, USA).

After sequencing of the 16 samples and assembly of the quality-controlled sequence data, 4,333,577 contigs, with an average read length of approximately $1,000 \mathrm{bp}$, were generated (see Additional file 1). Dietary yeast supplementation increased the relative abundance of 37 microbial species (see Additional file 2). The microbial species ( $>1 \%$ of the total community) that responded to dietary treatment are shown in Table 1. Ruminococcus albus and $R$. flavefaciens are cellulose-degrading bacteria [15], $R$. bromii degrades resistant starch and xylan, while $R$. obeum degrades complex deoxy sugars, such as rhamnose and fucose [16]. Several studies have reported the effectiveness of certain strains of S. cerevisiae at increasing the abundance and activities of dominant fiber-degrading rumen microorganisms, such as Fibrobacter and Ruminococcus spp. [4]. This study also revealed that the abundance of relatively unknown and less abundant ruminal cellulolytic microbial species, such as Rhodopseudomonas palustris and Sorangium cellulosum, responded to YEA treatment (see Additional file 2). Some of the microbial species such as $R$. obeum, Faecalibacterium prausnit$z i i$, and Enterococcus casseliflavus, that responded to YEA treatment are common human gut microbes and are not often detected in the rumen at high abundance $(>1 \%)$, therefore, further studies are needed to quantify these bacteria via quantitative polymerase chain reaction.

Yeast additives maintain efficient rumen function necessary for the growth and activities of cellulolytic bacteria by increasing ruminal $\mathrm{pH}$ [1]. Yeast additives stimulate the growth of lactate-fermenting bacteria via supply of

Table 1 Relative abundance of microbial species (> 1\% of total sequences) affected by dietary treatment in beef steers fed no or $15 \mathrm{~g} / \mathrm{d}$ of live yeast product

\begin{tabular}{lllll}
\hline Microbial species & \multicolumn{2}{l}{ Treatment $^{\mathrm{a}}$} & SE & P-value \\
\cline { 2 - 3 } & CON & YEA & & \\
\hline Faecalibacterium prausnitzii & 0.83 & 1.45 & 0.08 & 0.01 \\
Ruminococcus flavefaciens & 0.28 & 1.21 & 0.13 & 0.01 \\
Oscillibacter valericigenes & 0.56 & 1.16 & 0.13 & 0.01 \\
Ruminococcus bromii & 0.70 & 1.66 & 0.18 & 0.01 \\
Methanobrevibacter ruminantium & 0.55 & 1.01 & 0.14 & 0.04 \\
Ruminococcus obeum & 0.35 & 1.22 & 0.10 & 0.01 \\
Enterococcus casseliflavus & 0.31 & 1.04 & 0.27 & 0.05 \\
Megasphaera elsdenii & 0.29 & 1.13 & 0.20 & 0.05 \\
Ruminococcus albus & 0.26 & 1.36 & 0.09 & 0.01 \\
\hline
\end{tabular}

${ }^{\mathrm{a}} \mathrm{CON}=$ no yeast treatment; $\mathrm{YEA}=15 \mathrm{~g} / \mathrm{d}$ of live yeast product (PMI, Arden Hills, MN, USA) vitamins and amino acids essential for their growth [4] and/or outcompeting lactate-producers (such as Streptococcus bovis) for sugar utilization, thereby preventing ruminal lactate accumulation [1]. In this study, the relative abundance of Megasphaera elsdenii, a lactate-fermenting bacterium, and two species of Desulfovibrio (D. desulfuricans and D. vulgaris; see Additional file 2) known to oxidize lactate to acetate [17], were increased by YEA. It is important to note that lactate concentration was not influenced, probably because the diet fed was non-acidotic (as reported in our companion paper [7]).

The increased relative abundance of Methanobrevibacter ruminantium, a prominent member of methanogenic archaea, observed in this study is probably due to the increased abundance of fiber-degrading bacteria, especially Ruminococcus albus, a carbohydrate-fermenting, $\mathrm{H}_{2}$-producing organism [18]. This might be linked to $\mathrm{H}_{2}$ transfer between $\mathrm{H}_{2}$-producing cellulolytic bacteria and methanogenic archaea [19]. Fiber is fermented to volatile fatty acids, ammonia, $\mathrm{H}_{2}$, and $\mathrm{CO}_{2}$ in the rumen [20]. Rumen methanogens, such as $M$. ruminantium, use $\mathrm{H}_{2}$ as a substrate to reduce $\mathrm{CO}_{2}$ to methane [21]. Results of studies on the effects of strains of $S$. cerevisiae on ruminal methane production have been conflicting. An in vitro study by Chaucheyras-Durand et al. [22] revealed that a certain live yeast strain increased growth of acetogenic bacteria that can outcompete methanogens by utilizing $\mathrm{H}_{2}$ and $\mathrm{CO}_{2}$ to produce acetate. Newbold and Rode [23] evaluated the effects of several yeast strains on methane production and reported either no effect or decreased methane production. Our results suggest that YEA treatment might increase the amount of ruminal $\mathrm{CH}_{4}$ produced due to the increased abundance of $M$. ruminantium; however, we believe that $\mathrm{CH}_{4}$ production per unit of milk or meat will probably be reduced through improved ruminal fiber degradation and feed conversion efficiency.

To our knowledge, this study is the first to evaluate the influence of dietary treatment with yeast product on differentially abundant gene (DEG). A total of 154. DEGs were obtained (fold change $>2$; FDR $<0.01$ ). Exactly 139 genes were upregulated in the YEA treatment whereas 15 genes were upregulated in CON. The details of the DEGs, including gene IDs and statistical information, are shown in Additional file 3. None of the genes enriched in CON were annotated in KEGG. KEGG annotation analysis of the upregulated genes in YEA revealed that 10 pathways were enriched (Table 2). These 10 pathways were related to folding, sorting and degradation, translation, membrane transport, and metabolisms of vitamins and co-factors, energy, terpenoids and polyketides, amino acids, and carbohydrate pathways at KEGG orthology level 2 (Table 2). These confirm the results of our companion paper [6] in which we reported 
Table 2 KEGG orthology annotation of differential genes enriched in beef steers fed $15 \mathrm{~g} / \mathrm{d}$ of live yeast product

\begin{tabular}{|c|c|c|}
\hline KO level 2 & KO level 3 & $\mathrm{KO}$ level function \\
\hline Carbohydrate metabolism & $\begin{array}{l}\text { Amino sugar and nucleotide sugar metabolism } \\
\text { [PATH: ko00520] }\end{array}$ & $\begin{array}{l}\text { UDP-N-acetyl-2-amino-2-deoxyglucuronate } \\
\text { dehydrogenase; } \\
\text { Beta- } \mathrm{N} \text {-acetylhexosaminidase }\end{array}$ \\
\hline Energy metabolism & Oxidative phosphorylation [PATH: ko00190] & $\begin{array}{l}\text { Ubiquinol-cytochrome c reductase } \\
\text { cytochrome b subunit; } \\
\text { Cytochrome c oxidase subunit } 2 \text {. }\end{array}$ \\
\hline Glycan biosynthesis and metabolism & $\begin{array}{l}\text { Liposaccharide biosynthesis } \\
\text { [PATH: ko00540] }\end{array}$ & $\begin{array}{l}\text { 3-deoxy-manno-octulosonate } \\
\text { cytidylyltransferase }\end{array}$ \\
\hline Metabolism of cofactors and vitamins & $\begin{array}{l}\text { Pantothenate and CoA biosynthesis } \\
\text { [PATH: ko00770] }\end{array}$ & $\begin{array}{l}\text { Dephospho-CoA kinase; } \\
\text { Pantoate--beta-alanine ligase }\end{array}$ \\
\hline Metabolism of other amino acids & $\begin{array}{l}\text { Glutathione metabolism } \\
\text { [PATH: ko00480] }\end{array}$ & Aminopeptidase $\mathrm{N}$ \\
\hline Metabolism of other amino acids & $\begin{array}{l}\text { Beta-alanine metabolism } \\
\text { [PATH: ko00410] }\end{array}$ & Pantoate--beta-alanine ligase \\
\hline Metabolism of terpenoids and polyketides & $\begin{array}{l}\text { Polyketide sugar unit biosynthesis } \\
\text { [PATH: ko00523] }\end{array}$ & dTDP-4-dehydrorhamnose reductase \\
\hline Folding, sorting and degradation & $\begin{array}{l}\text { Protein export } \\
\text { [PATH: ko03060] }\end{array}$ & Preprotein translocase subunit SecE \\
\hline Translation & $\begin{array}{l}\text { Ribosome } \\
\text { [PATH: ko03010] }\end{array}$ & $\begin{array}{l}\text { Large subunit ribosomal protein L15; Large } \\
\text { subunit ribosomal protein L10 }\end{array}$ \\
\hline Membrane transport & $\begin{array}{l}\text { Bacterial secretion system } \\
\text { [PATH: ko03070] }\end{array}$ & Preprotein translocase subunit SecE \\
\hline
\end{tabular}

positive correlations between some bacterial genera that responded to yeast treatment and metabolites involved in metabolism of carbohydrates and amino acids. The DEGs related to carbohydrate metabolism were UDP-Nacetyl-2-amino-2-deoxyglucuronate dehydrogenase and $\beta$-N-acetylhexosaminidase, both of which are involved in metabolism of amino and nucleotide sugars, which are components of structural polysaccharides. The DEGs related to oxidative phosphorylation were ubiquinol-cytochrome $\mathrm{c}$ reductase cytochrome b subunit and cytochrome c oxidase subunit 2 , both of which are components of the mitochondrial respiratory chain of $S$. cerevisiae that catalyzes the reduction of oxygen to water [24]. This indicates an oxygen-scavenging activity, one of the modes of action by which $S$. cerevisiae improves rumen function. Oxygen is toxic to rumen microbes; therefore, lowering the redox potential in the rumen improves the growing conditions for anaerobic rumen microbes [25]. This probably explains increased relative abundance of strictly anaerobic bacteria, such as Oscillibacter valericigenes and F. prausnitzii, observed in this study.

Lipopolysaccharides are components of gram-negative bacterial cell walls and are required for growth, virulence, and drug resistance of these bacteria [26]. The population of gram-negative bacteria accounts for up to $80 \%-90 \%$ of the total ruminal bacterial population [27]. In this study, increased lipopolysaccharide biosynthesis probably indicates improved ruminal bacterial growth. Feeding live yeast creates favorable conditions for growth and activities of ruminal bacteria through increased $\mathrm{pH}$, lower redox potential, and supply of growth factors [25].

Rumen microbes are able to synthesize pantothenic acid and other B vitamins [28]; however, the net vitamin synthesis in the rumen may not be adequate to satisfy the nutritional requirements of the animals, especially in high-producing or growing animals [29]. Saccharomyces cerevisiae is capable of de novo biosynthesis of pantothenic acid and co-enzyme A via the activities of pantoate-beta-alanine ligase (using pantoate and alanine as substrates) and dephospho-CoA kinase (using dephospho-CoA as a substrate), respectively [30]. This explains the enriched pantothenic acid and CoA biosynthesis pathway and increased abundance of Megasphaera elsdenii and Desulfovibrio spp., in YEA treatment because lactate-utilizers require vitamins for their growth and activities [31]. Aminopeptidase N, also called alanyl aminopeptidase, is a hydrolase enzyme that catalyzes the cleavage of alanine from $\mathrm{N}$-terminus of a dipeptide such as alanylglycine [32]. Enrichment of aminopeptidase $\mathrm{N}$ is probably due to increased demand of alanine as a substrate for pantothenic acid synthesis by $S$. cerevisiae.

Enrichment of pathways related to ribosome and protein export probably indicates increased microbial protein synthesis. Ribosomes are organelles that catalyze mRNA-directed protein synthesis in all organisms [33]. In our companion study, we observed lower ammonia-N in steers receiving YEA, which was partly due to its increased uptake by rumen microbes for protein synthesis. 

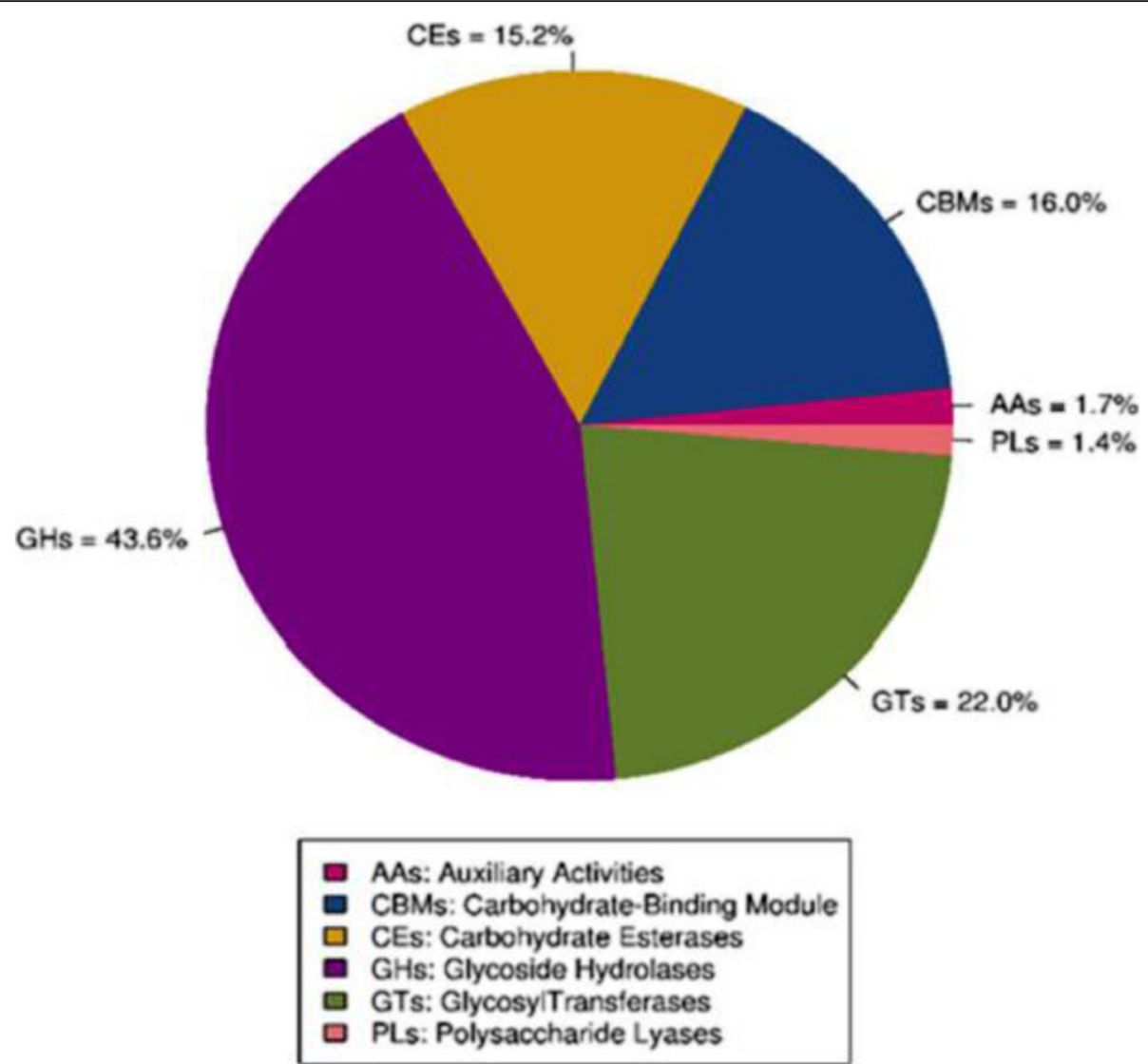

Fig. 1 Distribution of the carbohydrate-active enzymes

Table 3 Carbohydrate-active enzymes (CAZy) database annotation of differential genes enriched in beef steers fed $15 \mathrm{~g} / \mathrm{d}$ of live yeast product

\begin{tabular}{|c|c|c|}
\hline Family & CAZy-Class $^{a}$ & Activities $^{\mathrm{b}}$ \\
\hline CBM37 & CBM & $\begin{array}{l}\text { Polysaccharide-degrading enzymes with broad specificity for xylan, chitin, } \\
\text { microcrystalline and cellulose }\end{array}$ \\
\hline $\mathrm{GH} 16$ & $\mathrm{GH}$ & $\begin{array}{l}\text { Xyloglucosyltransferase; endo-1,4-beta-galactosidase; endo-1,3-beta-glucanase; endo-1,3 } \\
\text { (4)-beta-glucanase; licheninase; beta-agarase; carrageenase; xyloglucanase }\end{array}$ \\
\hline $\mathrm{GH} 23$ & $\mathrm{GH}$ & Peptidoglycan lyase \\
\hline $\mathrm{GH} 3$ & $\mathrm{GH}$ & $\begin{array}{l}\text { Beta-glucosidase; xylan1,4-beta-xylosidase; beta-N-acetylhexosaminidase; 1,3-beta-glucosidase; } \\
\text { 1,4-beta-glucosidase; exo-1,3-1,4-glucanase; alphalpha-L-arabinofuranosidase }\end{array}$ \\
\hline GT2 & GT & $\begin{array}{l}\text { Cellulose synthase; chitin synthase; dolichyl-phosphate beta-D-mannosyltransferase; } \\
\text { dolichyl-phosphate beta-glucosyltransferase; N-acetylglucosaminyltransferase; } \\
\text { N-acetylgalactosaminyltransferase; hyaluronan synthase; chitin oligosaccharide } \\
\text { synthase; beta-1,3-glucan synthase; beta-1,4-mannan synthase; } \\
\text { alpha-1,6-mannosyltransferase; alpha-1,3-L-rhamnosyltransferase }\end{array}$ \\
\hline GT4 & GT & $\begin{array}{l}\text { Sucrose synthase; sucrose-phosphate synthase; alpha-glucosyltransferase; } \\
\text { lipopolysaccharide N-acetylglucosaminyltransferase; 1,2-diacylglycerol } \\
\text { 3-glucosyltransferase; diglucosyl diacylglycerol synthase; digalactosyldiacylglycerol synthase }\end{array}$ \\
\hline GT83 & GT & 4-amino-4-deoxy-beta-L-arabinosyltransferase; lipopolysaccharide core alpha-galacturonosyl transferase \\
\hline GT9 & GT & Lipopolysaccharide N-acetylglucosaminyltransferase; heptosyltransferase \\
\hline
\end{tabular}

${ }^{a} C B M$ Carbohydrate binding modules, GH glycoside hydrolases, GT Glycosyltransferases

${ }^{\mathrm{b}}$ According to carbohydrate-active enzyme database (http://www.cazy.org/) 
In this study, yeast supplementation improved rumen microbial growth, specifically the cellulolytic bacteria. Since cellulolytic bacteria have a high preference for ammonia-N [34], it was expected that utilization of ammonia- $\mathrm{N}$ by the rumen microbes for protein synthesis would increase.

The rumen contains several carbohydrate-active enzymes that are produced by rumen microorganisms and required for hydrolysis of plant cell-wall polysaccharides. A total of 148,586 predicted genes were annotated to the CAZy database, a database containing 6 classes of CAZy: glycoside hydrolases (GHs), glycosyltransferases (GTs), polysaccharide lyases (PLs), carbohydrate binding modules (CBM), carbohydrate esterases (CEs), and auxiliary activities (AAs). The distribution of the annotated genes is shown in Fig. 1. Annotation of the DEGs revealed that 3 genes belonged to GH3, GH16, and GH23 families; 4 genes belonged to GT2, GT4, GT9, and GT83 families; and 1 gene belonged to the CBM37 family (Table 3). Families of enzymes belonging to GHs and CBMs are polysaccharides-degrading enzymes produced by ruminal cellulolytic bacteria [35]. Increased abundance of GHs and CBMs was due to increased growth of cellulolytic bacteria in beef steer fed YEA. Glycosyltransferases represent a class of enzymes involved in synthesizing glycosidic bonds for the biosynthesis of polysaccharides such as lipopolysaccharides [36]. This explains the enriched lipopolysaccharides biosynthesis pathway observed in steers fed YEA.

\section{Conclusion}

This study provides new insights into the mode of action of live yeast, such as evidence of oxygen consumption and increased abundance of carbohydrate-active enzymes. Taken together, these results confirm the effectiveness of a live S. cerevisiae product at improving rumen function by increasing the abundance of cellulolytic bacteria, lactic acid-utilizing bacteria, and carbohydrate-active enzymes in the rumen.

\section{Additional files}

Additional file 1: Details of sequence data. (XLSX $14 \mathrm{~kb}$ )

Additional file 2: Effects of live yeast supplementation on rumen microbial species. (DOCX $14 \mathrm{~kb}$ )

Additional file 3: List of differentially abundant genes. (XLSX $38 \mathrm{~kb}$ )

\section{Abbreviations}

bp: Base pair; CAZy: Carbohydrate-active enzymes; CD-HIT: Cluster database at high identity with tolerance; CON: Control treatment; DEG: Differentially abundant genes; DNA: Deoxyribonucleic acid; FDR: False discovery rate; KEGG: Kyoto Encyclopedia of Genes and Genomes; QUAST: Quality Assessment Tool for Genome Assemblies; rRNA: Ribosomal ribonucleic acid; YEA: Live yeast treatment

\section{Acknowledgements}

The authors are grateful to Hank Schweickart for the daily care and treatment of the animals.

\section{Authors' contributions}

$\mathrm{IO}$ and $\mathrm{KA}$ conceived and designed the experiment. $\mathrm{IO}$ and $\mathrm{J}$ performed the experiment, $\mathrm{IO}$ and FB analyzed the data. $\mathrm{IO}$ wrote the paper. CM edited and reviewed the manuscript. All authors read and approved the final manuscript.

\section{Funding}

This study (KYSU-000058) was partially supported by funds from Land O' Lakes Inc. and the US Department of Agriculture's National Institute of Food and Agriculture Evans-Allen project 1008985.

\section{Availability of data and materials}

All data generated or analyzed are available from the corresponding author on request.

\section{Ethics approval}

The research protocol (protocol number 18-001) was reviewed and approved by the Institutional Animal Care and Use Committee of Kentucky State University.

\section{Consent for publication}

Not applicable.

\section{Competing interests}

The authors declare that they have no competing interests.

Received: 7 March 2019 Accepted: 9 July 2019

Published online: 04 September 2019

\section{References}

1. Chaucheyras-Durand F, Chevaux E, Martin C, Forano E. Use of yeast probiotics in ruminants: Effects and mechanisms of action on rumen $\mathrm{pH}$, fiber degradation, and microbiota according to the diet. In: Rigobelo E, editor. Probiotic in Animals. Rijeka, Croatia: IntechOpen; 2012. p. 119-52. https://doi.org/10.5772/50192.

2. Nisbet DJ, Martin SA. The effect of Saccharomyces cerevisiae culture on lactate utilization by the ruminal bacterium Selenomonas ruminantium. J Anim Sci. 1991;69:4628-33.

3. Ercolini D. High-throughput sequencing and metagenomics: moving forward in the culture-independent analysis of food microbial ecology. Appl Environ Microbiol. 2013;79:3148-55.

4. Jiang Y, Ogunade IM, Qi S, Hackmann TJ, Staples CR, Adesogan AT. Effects of the dose and viability of Saccharomyces cerevisiae. 1. Diversity of ruminal microbes as analyzed by Illumina MiSeq sequencing and quantitative PCR. J Dairy Sci. 2017:100:325-42

5. Mann E, Wetzels SU, Wagner M, Zebeli Q, Schmitz-Esser S. Metatranscriptome sequencing reveals insights into the gene expression and functional potential of rumen wall bacteria. Front Microbiol. 2018;9:43.

6. Ogunade I, Schweickart H, McCoun M, Cannon K, McManus C. Integrating 165 rRNA sequencing and LC-MS-based metabolomics to evaluate the effects of live yeast on rumen function in beef cattle. Animals. 2019;9(1):28.

7. Ogunade IM, Schweickart H, Andries K, Lay J. Monensin alters the functional and metabolomics profile of rumen microbiota in beef cattle. Animals. 2018:8:211.

8. Qin J, Li R, Raes J, Arumugam M, Burgdorf KS, Manichanh C, et al. A human gut microbial gene catalogue established by metagenomic sequencing. Nature. 2010;464:59-65.

9. Peng Y, Leung HCM, Yiu SM, Chin FYL. IDBA-UD: a de novo assembler for single-cell and metagenomic sequencing data with highly uneven depth. Bioinformatics. 2012;28:1420-8.

10. Gurevich A, Saveliev V, Vyahhi N, Tesler G. QUAST: quality assessment tool for genome assemblies. Bioinformatics. 2013;29(8):1072-5.

11. Wood DE, Salzberg SL. Kraken: ultrafast metagenomic sequence classification using exact alignments. Genome Biol. 2014;15:46.

12. Zhu W, Lomsadze A, Borodovsky M. Ab initio gene identification in metagenomic sequences. Nucleic Acids Res. 2010;38:132.

13. Li W, Godzik A. CD-HIT: a fast program for clustering and comparing large sets of protein or nucleotide sequences. Bioinformatics. 2006;22:1658-9. 
14. Anders S, Huber W. Differential expression of RNA-Seq data at the gene level-the DESeq package. Heidelberg: European Molecular Biology Laboratory (EMBL); 2012.

15. Flint HJ, Bayer EA, Rincon MT, Lamed R, White BA. Polysaccharide utilization by gut bacteria: potential for new insights from genomic analysis. Nat Rev Microbiol. 2008:6:121-31.

16. Reichardt N, Duncan SH, Young P, Belenguer A, Leitch CM, Scott KP, et al. Phylogenetic distribution of three pathways for propionate production within the human gut microbiota. ISME J. 2014;8:1323.

17. Vita $\mathrm{N}$, Valette $\mathrm{O}$, Brasseur $\mathrm{G}$, Lignon $\mathrm{S}$, Denis $\mathrm{Y}$, Ansaldi $\mathrm{M}$, et al. The primary pathway for lactate oxidation in Desulfovibrio vulgaris. Front Microbiol. 2015; 6:606

18. Iannotti EL, Kafkewitz D, Wolin MJ, Bryant MP. Glucose fermentation products of Ruminococcus albus grown in continuous culture with Vibrio succinogenes: changes caused by interspecies transfer of H2. J Bacteriol. 1973;114:1231-40.

19. Chassard C, Delmas E, Robert C, Bernalier-Donadille A. The cellulosedegrading microbial community of the human gut varies according to the presence or absence of methanogens. FEMS Microbiol Ecol. 2010;74:205-13.

20. Loor JJ, Elolimy AA, McCann JC. Dietary impacts on rumen microbiota in beef and dairy production. Anim Front. 2016;6:22-9.

21. Hook SE, Wright ADG, McBride BW. Methanogens: methane producers of the rumen and mitigation strategies. Archaea. 2010;2010:945785.

22. Chaucheyras-Durand F, Fonty $\mathrm{G}$, Bertin G, Gouet P. In vitro $\mathrm{H}_{2}$ utilization by a ruminal acetogenic bacterium cultivated alone or in association with an archaea methanogen is stimulated by a probiotic strain of Saccharomyces cerevisiae. Appl Environ Microbiol. 1995;61:3466-7.

23. Newbold CJ, Rode LM. Dietary additives to control methanogenesis in the rumen. Int Congr Ser. 2006;1293:138-47.

24. Beattie DS, Jenkins HC, Howton MM. Biochemical evidence for the orientation of cytochrome $b$ in the yeast mitochondrial membrane in the eight-helix model. Arch Biochem Biophys. 1994;312:292-300.

25. Chaucheyras-Durand F, Walker ND, Bach A. Effects of active dry yeasts on the rumen microbial ecosystem: past, present and future. Anim Feed Sci Technol. 2008;145:5-26.

26. Kondo Kl, Doi H, Adachi H, Nishimura Y. Synergistic effect of CMP/KDO synthase inhibitors with antimicrobial agents on inhibition of production and release of vero toxin by enterohaemorrhagic Escherichia coli O157: H7. Bioorg Med Chem Lett. 2004;14:467-70.

27. Krause DO, Nagaraja TG, Wright AD, Callaway TR. Board invited review: rumen microbiology: leading the way in microbial ecology. J Anim Sci. 2013:91:331-41.

28. Volker D, Hüther $L$, Daş G, Abel H. Pantothenic acid supplementation to support rumen microbes? Arch Anim Nutr. 2011;65:163-73.

29. NRC. Nutrient Requirements of Dairy Cattle. 7th rev. ed. Washington, DC: National Academies Press; 2001

30. White WH, Gunyuzlu PL, Toyn JH. Saccharomyces cerevisiae is capable of de novo pantothenic acid biosynthesis involving a novel pathway of betaalanine production from spermine. J Biol Chem. 2001;276:10794-800.

31. Wolin MJ, Miller TL. Microbe-microbe interactions. In: Hobson PN, editor. The rumen microbial ecosystem. London: Elsevier Applied Science; 1988. p. 343-59.

32. Luan $Y, X u$ W. The structure and main functions of aminopeptidase N. Curr Med Chem. 2007;14:639-47.

33. Alberts B, Johnson A, Lewis J, Raff M, Roberts K, Walter P. The Endoplasmic Reticulum. In Molecular Biology of the Cell. 4th ed. New York: Garland Science; 2002.

34. Bryant MP, Robinson IM. Studies on the nitrogen requirements of some ruminal cellulolytic bacteria. Appl Microbiol. 1961;9:96-103.

35. Flint HJ, Scott KP, Duncan SH, Louis P, Forano E. Microbial degradation of complex carbohydrates in the gut. Gut Microbes. 2012:3(4):1-18.

36. Lairson LL, Henrissat B, Davies GJ, Withers SG. Glycosyltransferases: structures, functions, and mechanisms. Annu Rev Biochem. 2008:77:521-55.

Ready to submit your research? Choose BMC and benefit from:

- fast, convenient online submission

- thorough peer review by experienced researchers in your field

- rapid publication on acceptance

- support for research data, including large and complex data types

- gold Open Access which fosters wider collaboration and increased citations

- maximum visibility for your research: over $100 \mathrm{M}$ website views per year

At $\mathrm{BMC}$, research is always in progress.

Learn more biomedcentral.com/submissions 